\title{
A CLINICOPATHOLOGICAL STUDY TO ANALYSE THE IMPORTANCE OF HISTOPATHOLOGICAL EXAMINATION IN DIAGNOSIS OF EXCISED CONJUNCTIVAL LESIONS
}

\author{
Pandiaraj Saravana Sankar1, Chandran Indhu², Nataraja Rathinam Sudha Priyadharsini ${ }^{3}$, Manoharan Suhanya ${ }^{4}$, \\ Eswaramoorthy Jeeva ${ }^{5}$, Manimozhi Sundaravathani ${ }^{6}$, Vetrichelvan Dhivya ${ }^{7}$, Chandra Sekar Sangeetha Kala ${ }^{8}$
}

\begin{abstract}
${ }^{1}$ Assistant Professor, Department of Ophthalmology, Madurai Medical College, Madurai, Tamilnadu, India. ${ }_{2}^{2}$ Assistant Professor, Department of Ophthalmology, Madurai Medical College, Madurai, Tamilnadu, India. 3Senior Resident, Department of Ophthalmology, Madurai Medical College, Madurai, Tamilnadu, India. ${ }^{4}$ Senior Resident, Department of Ophthalmology, Madurai Medical College, Madurai, Tamilnadu, India. 5Junior Resident, Department of Ophthalmology, Madurai Medical College, Madurai, Tamilnadu, India. 6Junior Resident, Department of Ophthalmology, Madurai Medical College, Madurai, Tamilnadu, India. 7 Junior Resident, Department of Ophthalmology, Madurai Medical College, Madurai, Tamilnadu, India. 8Junior Resident, Department of Ophthalmology, Madurai Medical College, Madurai, Tamilnadu, India.
\end{abstract}

$$
\text { ABSTRACT }
$$

\section{BACKGROUND}

Squamous papilloma is a benign tumor that originates from human papillomavirus infection of conjunctiva. This tumor can occur in children and adults. It has a pink fibrovascular frond of tissue arranged in a sessile or pedunculated pattern. A pinguecula is small, yellowish nodule, bilateral and located at the nasal/temporal limbus. On histology, the stromal collagen has fragmentation and basophilic degeneration known as elastotic degeneration as the degenerated collagen stains positively when using histochemical stains for elastic fibre like the Verhoeff-Van Gieson stain.

Objectives of this study-

1. To analyse the importance of histopathological examination in confirming the diagnosis of various conjunctival lesions like ocular surface squamous neoplasia, malignant melanoma, granulomas.

2. To analyse the clinical presentation of various conjunctival lesions and to differentiate between benign and malignant lesions histopathologically (for early diagnosis of malignancy).

\section{MATERIALS AND METHODS}

This is a descriptive study of histopathology of conjunctival lesions from period of June 2015 to October 2017. Data included age, gender, laterality, gross feature, size, scleral fixity, corneal involvement, pain, congenital or acquired, progression, management, recurrence.

\section{RESULTS}

A total of 40 patients presented to our cornea clinic with conjunctival lesions from June 2015 to October 2017, of whom 23 patients were males (57\%) and $17(43 \%)$ were females. The age of presentation ranged from 13-70 years. In our study, the patients were clinically classified into eight categories- benign non-pigmented, pre-malignant non-pigmented, malignant non-pigmented, benign pigmented, malignant pigmented, premalignant pigmented, cyst and degeneration. Treatment options include, excision/excision with $3 \mathrm{~mm}$ tumour free margin biopsy, adjuvant conjunctival autograft, cryotherapy with AMG, corneal alcohol ablation, histopathological examination. In follow-up, recurrence is seen only in three cases of malignant lesions.

\section{CONCLUSION}

In any conjunctival lesion, excision biopsy followed by histopathological examination and regular follow up is mandatory.

\section{KEY WORDS}

Conjunctival Lesions, Pigmented, Malignant, Histopathology, Excision, Biopsy.

HOW TO CITE THIS ARTICLE: Sankar PS, Indhu C, Priyadharsini NRS, et al. A clinicopathological study to analyse the importance of histopathological examination in diagnosis of excised conjunctival lesions. J. Evolution Med. Dent. Sci. 2018;7(44):4727-4730, DOI: $10.14260 /$ jemds/2018/1055

\section{BACKGROUND \\ Papilloma}

Squamous papilloma is a benign tumor, that originates from human papillomavirus infection of conjunctiva. This tumor

'Financial or Other Competing Interest': None.

Submission 19-09-2018, Peer Review 14-10-2018,

Acceptance 20-10-2018, Published 29-10-2018.

Corresponding Author:

Vetrichelvan Dhivya,

No. 16, Mariamman Kovil Street,

Thuvakudy, Trichirapalli-620015,

Tamilnadu, India.

E-mail:dhivyamums@gmail.com

DOI: $10.14260 /$ jemds $/ 2018 / 1055$

\section{(c) $(1)$}

can occur in children and adults, and has a pink fibrovascular frond of tissue arranged in a sessile or pedunculated pattern (1). In children, the lesion is small, multiple, and found in the inferior fornix. In adults, it is solitary, more extensive, and extend to cover the full corneal surface resembling malignant squamous cell carcinoma.

\section{Degeneration}

A pinguecula is small, yellowish nodule, bilateral and located at the nasal/ temporal limbus. On histology, the stromal collagen has fragmentation and basophilic degeneration known as elastotic degeneration as the degenerated collagen stains positively when using histochemical stains for elastic fibre like the Verhoeff-Van Gieson stain. In pingueculas and 
pterygia overlying epithelium may show mild squamous metaplasia. Thus, with actinic damage to the skin, there is the possibility for future malignant transformation, though this occurs in rare cases with pingueculas and pterygia. If conjunctival squamous neoplasia occurs, it occurs over an area of preexisting elastotic degeneration. If epithelial hyperplasia, nuclear hyperchromasia and pleomorphism, \& excess mitotic figures are seen in an excised pinguecula or pterygium, a diagnosis of OSSN should be assigned.

Conjunctival-Intraepithelial Neoplasia (CIN) and Squamous Cell Carcinoma (Non-Pigmented)

CIN presents with ocular irritation/complaints of redness/ "growth on the eye (2)." Differentiation of benign from malignant surface tumours is difficult in slit lamp examination. Examination reveals a vascular limbal mass, within interpalpebral area. The affected area is thick, and may appear gelatinous/velvety. Gelatinous thickening, with superficial blood vessels, is common. CIN may mimic diffuse chronic conjunctivitis with mild thickening. Other less common presentations are sclerokeratitis, which is a focal corneal or scleral thinning with inflammation without any tumour mass (3). Biopsy is needed in atypical/ chronic scleritis/ conjunctivitis unresponsive to standard treatment. Hyperkeratosis is a characteristic feature of CIN and manifest as a white surface plaque, / "leukoplakia", which has no diagnostic significance (4). Neoplastic cells invade corneal epithelium, as a continuation of limbal CIN. Affected epithelium looks translucently grey, with sharply demarcated border (5).

\section{Aims and Objectives}

1. To analyse the importance of histopathological examination in confirming the diagnosis of various conjunctival lesions like ocular surface squamous neoplasia, malignant melanoma, granulomas.

2. To analyse the clinical presentation of various conjunctival lesions

3. To differentiate between benign and malignant lesions histopathologically (For early diagnosis of malignancy)

\section{MATERIALS AND METHODS}

It was a descriptive study. All patients with conjunctival lesions should undergo a detailed slit lamp examination and photograph the lesion preoperatively. In case of malignant lesions clinical staging of the lesion is done. Basic blood investigations like - random blood sugar, bleeding time and clotting time should be done before procedure. Informed written consent to be obtained from the patient. Patient is admitted as inpatient in ophthalmology ward. The procedure is done in Eye OT under strict aseptic precautions under suitable anaesthesia. The eye is draped, and speculum is applied, and specimen is obtained with 11 blade and forceps and scissors from the base and edge of the lesion. In case of doubtful malignant lesion cryotherapy has to be applied. In cases with large conjunctival lesions after excision leaving a large conjunctival defect - amniotic membrane graft should be done (6).

\section{Inclusion Criteria}

1. Consenting patients.

2. Patients with age more than 12 years, of either sex.
3. Presenting with clinical/histopathological evidence of conjunctival lesions.

\section{Exclusion Criteria}

1. Patients with infective conjunctival lesions like bacterial, chlamydial viral, fungal, rickettsial, protozoal, parasitic, conjunctivitis

2. Patients with bleeding diathesis.

3. Patients on anticoagulants.

\section{Analysis}

In this series, we have studied 40 cases of conjunctival lesions reported in our cornea clinic from June 2015 to October 2017. The following were the observations.

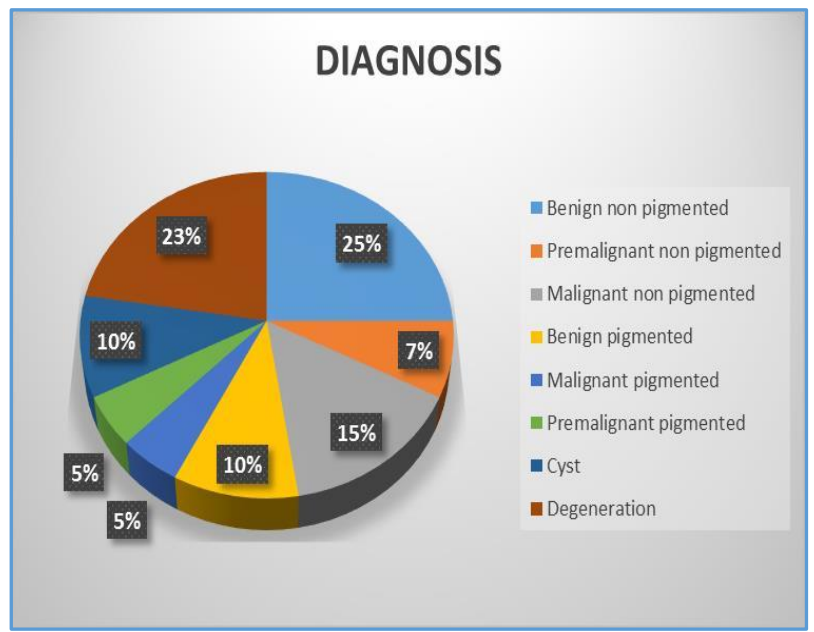

Age Distribution of Conjunctival Lesions Based on Histopathological Diagnosis [Percentage Distribution of Various Conjunctival Lesions]

\section{Distribution of Conjunctival Lesions Based on Their Management}

Among the 40 cases in the study group 10 cases underwent 3 $\mathrm{mm}$ tumour free margin excision.

\begin{tabular}{|c|c|}
\hline Type of Biopsy & No. of Cases \\
\hline Excision & 30 \\
\hline Excision with 3mm free margin & 10 \\
\hline Total & $\mathbf{4 0}$ \\
\hline
\end{tabular}

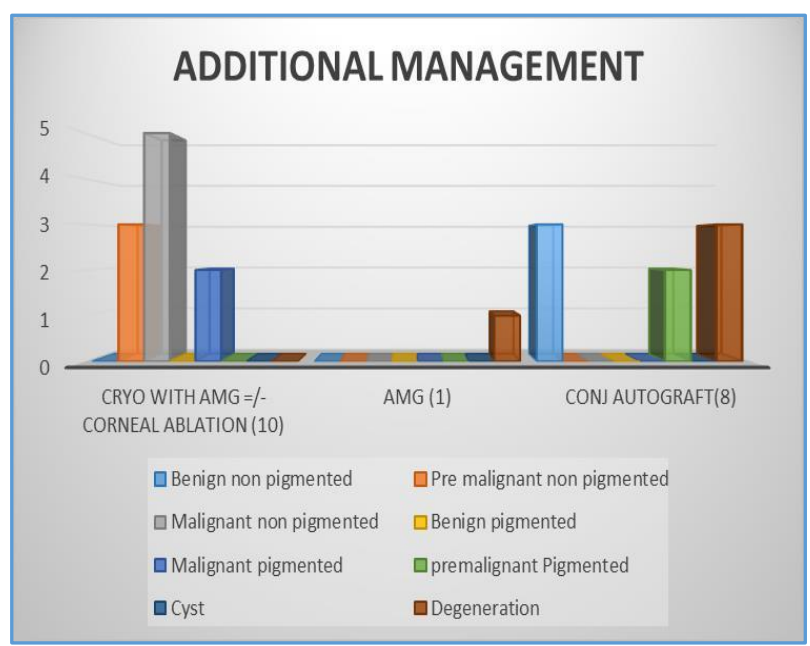

Distribution of Conjunctival Lesions Based on Additional Management done after Excision Biopsy 


\section{RESULTS}

Distribution of Conjunctival Lesion and Their Recurrence Among the study group of 40 cases 3 cases were recurrent and chi square test showed the association between the malignant lesion and recurrence with $p$ value 0.029 which is significant.
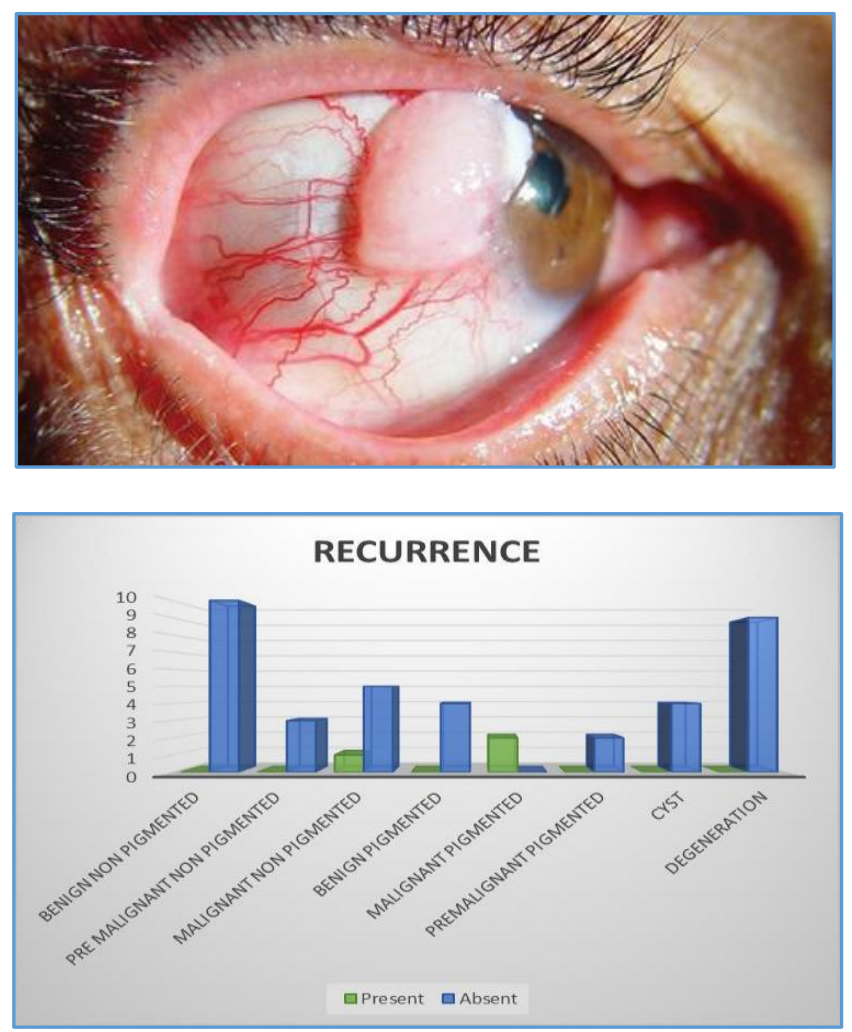

\section{DISCUSSION}

In this study, 40 patients participated, and the conjunctival biopsies were sent for the histopathological analysis. The following observations were made. Among them, $30 \%$ were < 20 years, $10 \%$ between $21-40$ years, $32.5 \%$ between $41-60$ years, $27.5 \%$ more than 60 years. It was noticed that benign non-pigmented tumors and benign pigmented lesions are more common in less than 40 years. In more than 60 years, degenerations and malignancies are more common. Among the distribution of various lesions based on their histopathological diagnosis - benign non-pigmented tumors are most common around 25\%, degenerations are second most common - 22.50. Third most common includes nonpigmented malignant lesions $15 \%$. Among the benign nonpigmented tumours -squamous papilloma (33\%) is most common and among degeneration- pterygium (33\%) and pinguecula $(33 \%)$ are most common. Among malignancies squamous cell carcinoma (37.5\%) is most common. In this study $42.5 \%$ were females and $57.5 \%$ were males. It was noted that there is a markedly high percent of malignant (75\%) and premalignant $(100 \%)$ lesions in males than females. There is no significant predilection of laterality of eyes in conjunctival lesions. The most common site for conjunctival lesions is the bulbar conjunctiva (87.5). In this study, from the gross features of conjunctival lesions indicates that non-pigmented malignancies most often (50\%) are leukoplakic white growth and benign non-pigmented lesions are most often (46\%) pinkish in colour. In this study it was noted that scleral fixity of the lesion is associated with malignancy most commonly (85\%) and it was statistically significant with $\mathrm{p}$ value of 0.029 . From the study it is noted that the number of lesions does not conclude the nature of the lesion. In the study it is obvious that larger the lesion size $>4 \mathrm{~mm}$ it is more likely to be malignant or premalignant $(73 \%)$ and most smaller lesions $<3 \mathrm{~mm}$ are benign (36\%). It was also concluded that all malignant lesions need wide excision with tumour free margin of about $3 \mathrm{~mm}(70 \%)$ and also additional application of cryotherapy and AMG (70\%). From the study it was noted that chronic lesions $>3$ years are more likely to be either degenerative $(38 \%)$ or benign (38\%). In this study it is seen that the presence of corneal involvement in conjunctival lesions does not conclude the nature of the lesion. In this study it is found out that pain is commonly associated with any type of malignant lesions (38.4\%) and mild pain may be a feature of traumatic granuloma or inclusion cysts $(30 \%)$. It is noted that progression is characteristically absent in benign lesions (50\%). It is also noted that acquired lesions are more common (95\%) than congenital lesions (5\%). It is also found that most OSSN are associated with HIV (50\%). From the study it was found that visual acuity cannot be correlated with the severity of the lesion because of lot of confounding factors like refractive error, cataract and diabetic retinopathy in these patients with conjunctival lesions. In this study it is found that recurrence after excision is markedly associated with malignant lesions (Pigmented/ Non-Pigmented) (30\%) and it was found to be statistically significant with $\mathrm{p}$ value of 0.029 .

\section{CONCLUSION}

In this study of conjunctival lesions, 40 cases were reported. Among the lesions, benign non-pigmented tumors are most common and degenerations are second most common. Among the benign non-pigmented tumors- squamous papilloma (1) is the most common and among degenerationspterygium and pingueculas are most common. Among malignancies- squamous cell carcinoma(7) is most common. Among pigmented lesions most common benign lesion is conjunctival melanosis and malignant is conjunctival melanoma (6). After proper treatment and regular followup, it has been noted that recurrence after excision is markedly associated with malignant lesions.

\section{REFERENCES}

[1] Shields JA, Shields CL. Tumours and pseudo tumours of the conjunctiva. In: Atlas of eyelid and conjunctival tumours. Philadelphia: Lippincott Williams \& Wilkins 1999: p. 199-334.

[2] Yeatts RP, Engelbrecht NE, Curry CD, et al. 5Fluorouracil for the treatment of intraepithelial neoplasia of the conjunctiva and cornea. Ophthalmology 2000;107(12):2190-5.

[3] Midena E, Angeli CD, Valenti M, et al. Treatment of conjunctival squamous cell carcinoma with topical 5fluorouracil. Br J Ophthalmology 2000;84(3):268-72.

[4] Brownstein S. Mucoepidermoid carcinoma of the conjunctiva with intraocular invasion. Ophthalmology 1981;88(12):1226-30. 


\section{Jemds.com}

[5] Frucht- Pery J, Rozenman Y. Mitomycin C therapy for corneal intraepithelial neoplasia. Am J Ophthalmology 1994;117(2):164-8.

[6] Paridaens D, Beekhuis H, van Den Bosch W, et al. Amniotic membrane transplantation in the management of conjunctival malignant melanoma and primary acquired melanosis with atypia. $\mathrm{Br}$ J Ophthalmology 2001;85(6):658-61.
Original Research Article

[7] Sherman M, Feldman K, Farahmand S, et al. Treatment of conjunctival squamous cell carcinoma with topical cidofovir. Am J Ophthalmol 2002;134(3):432-3. 